\title{
1995: An Important Inflection Point in Recent Geophysical History
}

\author{
Arthur Viterito* \\ Independent Researcher, USA \\ Submission: February 02, 2022; Published: February 14, 2022 \\ *Corresponding author: Arthur Viterito, Independent Researcher, Vero Beach, FL, 32966, USA
}

Abstract

A review of the geophysical literature reveals that a number of environmental systems changed rapidly in 1995 or shortly thereafter. A sudden jump in mid-ocean seismic activity initiated a cascade of changes to the thermohaline circulation, global temperatures, snow and ice cover in the Arctic, monsoon dynamics, El Niño characteristics, and dip pole movement. Acting in concert, there is a high probability that these changes drove global temperatures higher and have enabled global temperatures to remain elevated for the past 24 years.

Keywords: Climate change; Geophysical inflections; Mid-ocean seismic activity; Arctic amplification; Atlantic meridional overturning circulation; Atlantification

Abbreviations: AA: Arctic Amplification; ACE: Accumulated Cyclone Energy; AMO: Atlantic Multi-decadal Oscillation; AMOC: Atlantic Meridional Overturning Circulation; ATL: Atlantification; GT: Global Temperatures; ITCZ: Intertropical Convergence Zone; MOC: Meridional Overturning Circulation; MOSZSA: Mid-Ocean Spreading Zone Seismic Activity; NHSM: Northern Hemisphere Summer Monsoon; NOAA: National Oceanic and Atmospheric Administration; SAT: Surface Air Temperatures; SPG: Sub-Polar Gyre; SST: Sea Surface Temperatures; Sv: Sverdrups; WWSSN: World-Wide Standardized Seismic Network

\section{Introduction}

The 1960s and1970s saw the advent of powerful geoscientific monitoring tools, to include the digital processing of seismic data and the development of microwave sounding units to detect atmospheric temperatures. Beginning in 1979, lower tropospheric temperature datasets were compiled and published by researchers at the University of Alabama at Huntsville and Remote Sensing Systems. These datasets are arguably the most accurate quantitative assessments of the global lower troposphere for a variety of reasons. Foremost is the nearly universal spatial coverage offered by these orbiting platforms. By contrast, surfacebased measurements are unevenly distributed and large portions of the earth's surface have sparse or no data records. This is especially true for the earth's oceans, along with large continental tracts to include Siberia, Amazonia, Antarctica, Central Australia, the Sahara, Greenland, and northern Canada.

The introduction of the World-Wide Standardized Seismic Network (WWSSN) in the 1960s enabled the geophysical community to monitor global seismic activity, aiding the formulation of the grand, unifying theory we now call plate tectonics. The WWSSN was supplanted in the 1980s by the Global Seismic Network, a large network of high quality, broadband seismometers. This critical infrastructure allows geoscientists to monitor plate movements in real time, and greatly facilitates our ability to understand the structure and dynamics of the earth's crust, mantle and core.

In 1929, Alfred Wegner, a meteorologist by training, but best known for his theory of Continental Drift, wisely stated, "Scientists still do not appear to understand sufficiently that all earth sciences must contribute evidence toward unveiling the state of our planet .... It is only by combing the information furnished by all the earth sciences that we can hope to determine 'truth' here.... Further, we have to be prepared always for the possibility that each new discovery, no matter what science furnishes it, may modify the conclusions we draw" [1]. We may have been given an opportunity to test Wegner's axiom in 1995, as a number of geophysical systems appear to have reached critical inflection points that year or shortly thereafter. Moreover, a cascade of "cause and effect" pathways is evident when sound geophysical reasoning is applied.

\section{Discussion}

The strong relationship between mid-ocean spreading zone seismic activity (MOSZSA) and global temperatures (GT) has been well-documented [2-5]. Figure 1 shows MOSZSA (i.e., frequencies of moment magnitude events between 4 and 6) from 1979 through 
2021 (estimated). Of note is the fact that MOSZSA started to move towards a higher base level in 1995 and completed that shift 24 months later. The mean yearly MOSZSA from 1990 to 1994 was
224.6 events; from 1995 to 2000 , the mean annual frequency had jumped to 510.2 , a $127 \%$ increase.

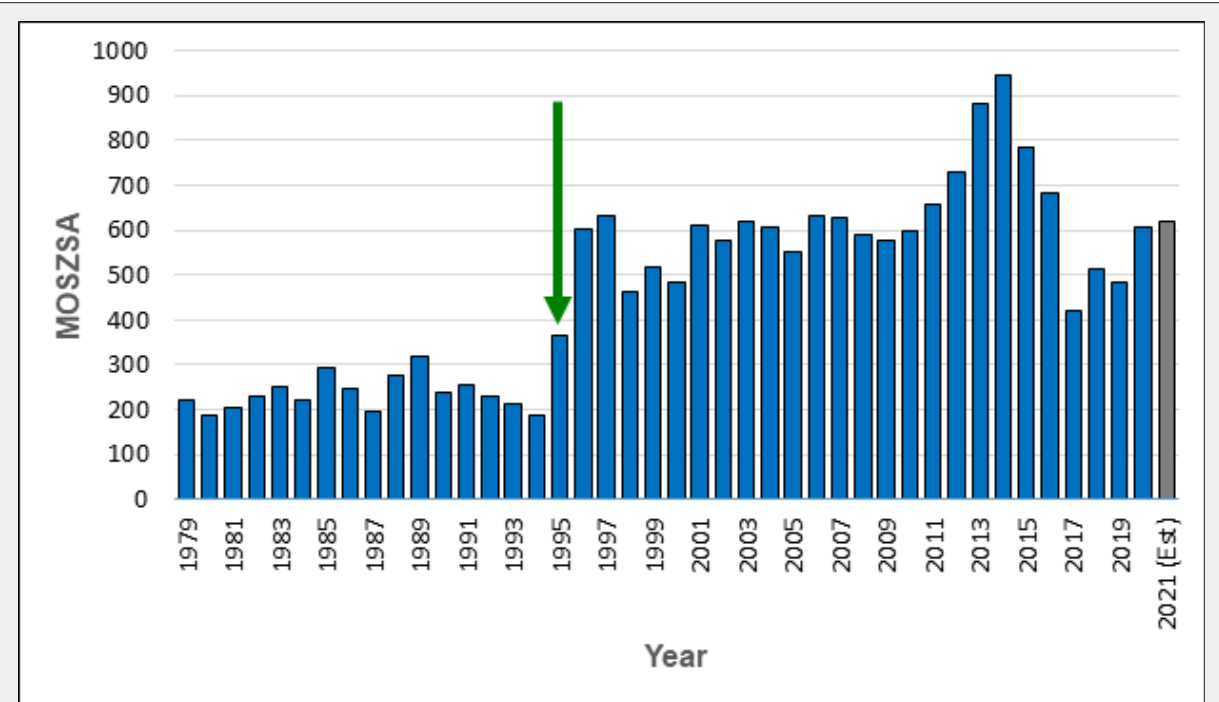

Figure 1: MOSZSA events (moment magnitude 4-6) for 1979-2021 (2021 is estimated through September). The green arrow identifies the1995 data point (http://ds.iris.edu/wilber3/find_event).

From 1996 to August 2021, the annual frequency has remained significantly elevated from pre-1995 levels, and now stands at 613.9 events per year. What must be kept in mind is that MOSZSA only captures seismic events with moment magnitudes of 4 through 6 , as events below 4 are difficult to detect by the Global Seismic Network. This represents the proverbial "tip of the iceberg" for the total number of seismic events, as the entire seismic envelope is a logarithmic phenomenon [6].

When disaggregated by ocean basin, the jump can be seen in all three major basins: Atlantic, Pacific, and Indian (Figure 2). While beyond the scope of this paper, it should be noted that the Atlantic frequencies peaked first (1996), followed by the Indian (1997), with the Pacific lagging (1998).

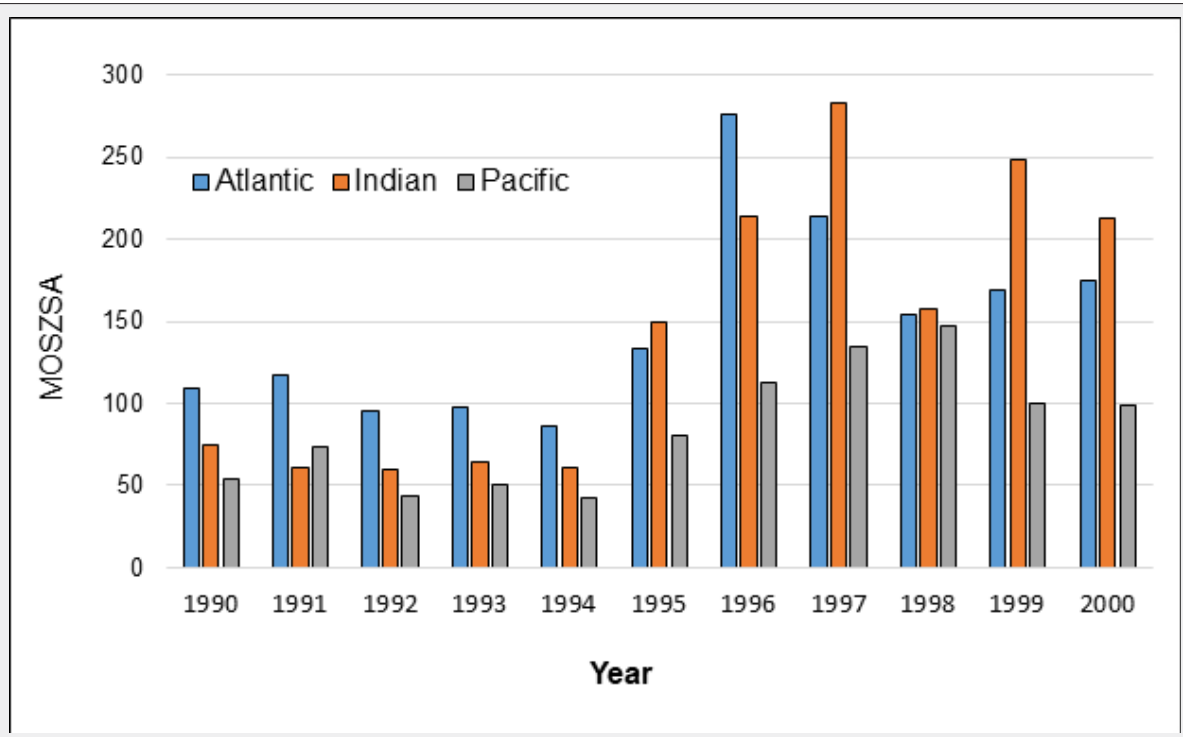

Figure 2: MOSZSA frequencies by basin, (1990-2000) (http://ds.iris.edu/wilber3/find_event).

As discussed elsewhere [2], MOSZSA is of great importance to GT as it is a proxy indicator of geothermal heat flow in these "hot" oceanic zones (e.g., hydrothermal vents, submarine volcanoes, etc.). Furthermore, MOSZSA is positively correlated with the total oceanic geothermal flux and increases (decreases) in MOSZSA correspond to increases (decreases) in the total flux from these spreading zones [7-9]. 
GT (Figure 3) shows a similar jump, but with a two-year lag relative to the MOSZSA jump. This sudden jump coincided with the 1997-1998 El Niño, the strongest El Niño on record, and comports with the idea that the climate system is "almost intransitive." This refers to non-linear systems where there are periods of relative stability punctuated by rapid change $[10,11]$.

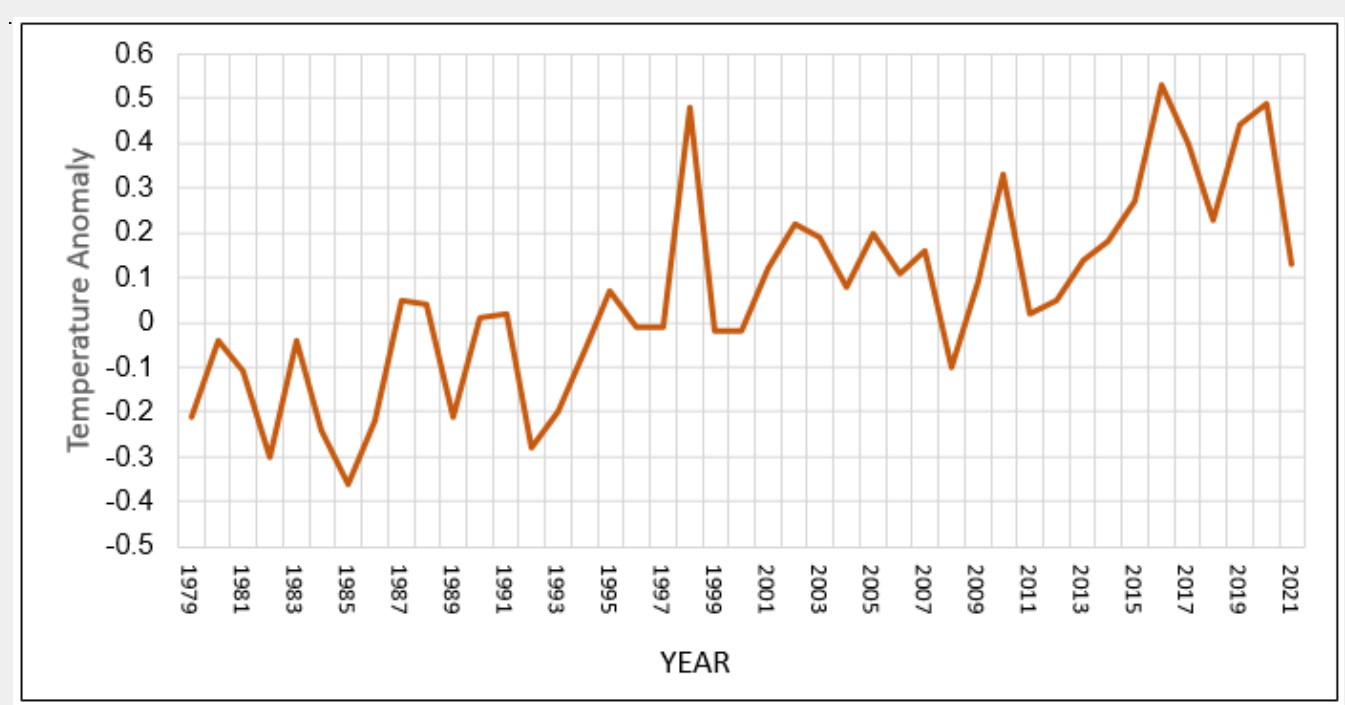

Figure 3: GT (1981-August 2021). University of Alabama-Huntsville Temperatures of the Lower Troposphere (http://vortex.nsstc. uah.edu/data/msu/v6.0/ttt/uahncdc_It_6.0.txt).

Figure 4 shows the fit of GT and MOSZSA from 1979 through 2021 (2021 is an estimate based upon temperatures and midocean seismic activity through August, 2021) with a two-year lag factored into the analysis (i.e., the 1979 MOSZSA is paired with the 1981 GT, the 1980 MOSZSA is paired with the 1982 GT, etc.). There is little doubt that the statistically significant, "goodness-offit" deserves further scrutiny $(r=0.72, p=9.43 \mathrm{E}-8)$.

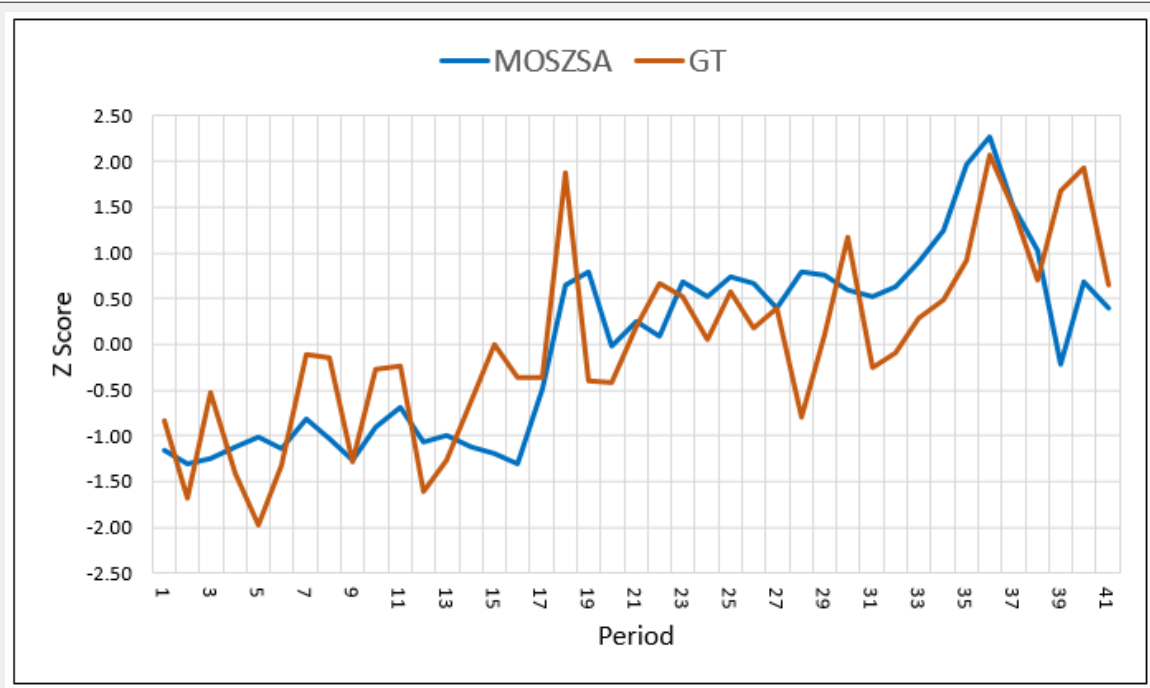

Figure 4: Plot of the standard scores of MOSZSA (1979-2019) and GT (1981- August 2021). GT is compiled from the University of Alabama-Huntsville Temperatures of the Lower Troposphere (http://vortex.nsstc.uah.edu/data/msu/v6.0/ttt/uahncdc_It_6.0.txt). MOSZSA is a compilation of 4 through 6 moment magnitude events from mid-ocean spreading zones and is extracted from the IRIS - Wilber 3 dataset (http://ds.iris.edu/wilber3/find_event).

The basis for the strong relationship between MOSZSA and GT is that geothermal flux in the mid-ocean zones can 1) strengthen the thermohaline circulation and 2) lessen the vertical stability of water columns in the Arctic. With regard to the dynamics of the thermohaline circulation, Ballarotta et al. [12] state that the global thermohaline circulation is intensified by geothermal heating of the ocean bottom by approximately 5 Sverdrups (Sv) ( $1 \mathrm{~Sv}=1$ million cubic meters per second). Thompson \& Johnson [13] report enhanced flow off the flanks of the East Pacific Rise in response to geothermal inputs. Downes et al. [14] demonstrate 
that geothermal heating alters the global overturning circulation and intensifies the Antarctic Circumpolar Current by 3-5Sv. They also recommend that geothermal heating be incorporated into global climate models. Adcroft et al. [15] show that geothermal heat can increase Pacific overturning by $1.8 \mathrm{~Sv}$, or $25 \%$ higher than it would be if there were no heating of the ocean bottom. Hoffmann \& Morales-Maqueda [16] show that geothermal heating is responsible for heating bottom waters by $0.4^{\circ} \mathrm{C}$. This decrease in bottom-water stability enhances formation rates in the bottom waters of the Atlantic and the Pacific, which, in turn, intensifies the Atlantic Meridional Overturning Circulation (AMOC). This intensification causes the North Atlantic western boundary current to warm up to $1.5^{\circ} \mathrm{C}$. Urakawa \& Hasumi [17] show that geothermal heating in the Indo-Pacific basin can also increase the intensity of the AMOC. Mullarney et al. [18], employing twodimensional box models, find that geothermal heating promotes a more vigorous overturning (10\%) compared to the absence of geothermal heating. In agreement, Scott et al. [19] demonstrate that the thermohaline circulation is enhanced several Sv higher with geothermal bottom heating. Finally, Patera \& Boning [20] show that the warming of Antarctic Bottom Water has strengthened the AMOC approximately $5 \%$ to $10 \%$ in response to density changes in the deep South Atlantic.

In addition to enhancing the thermohaline circulation, geothermal flux from mid-ocean spreading zones can also transfer heat to the ocean surface via thermobaric convection. Carmack et al. [21] show that geothermal heating of the bottom waters of the Arctic Ocean is sufficient to trigger thermobaric convection that can promote double diffusive transfer of heat to the surface. Bjork \& Winsor [22] show that geothermally driven convection is a significant process in the vertical transfer of heat in the Eurasian Basin. McPhee [23] comes to a similar conclusion for the Southern Ocean and shows that thermobaric convection may play an important role in polynya formation, which may significantly affect the global climate.

In effect, geothermal heating increases both advection and convection in the global ocean and this serves to transport large quantities of heat into the Arctic and North Atlantic Oceans. The warming of the North Atlantic and the Arctic helps to drive a phenomenon known as "Arctic Amplification" (AA), a hallmark of the most recent warming. Holland \& Bitz [24] posit that a series of positive feedbacks are responsible, as warming leads to reduced snow and ice cover, which lowers albedo and strengthens the absorption of solar radiation. Pistone et al. [25] report that satellite analysis reveals a strong relationship between sea ice area and planetary albedo. They go on to say that Arctic albedo decreased from 0.52 to 0.48 during the 1979 to 2011 timeframe. This is equivalent to adding $6.4 \pm 0.9 \mathrm{~W} / \mathrm{m}^{2}$ of solar input into the Arctic. Other feedbacks and forcings include changes to permafrost, vegetation, and freshwater budgets. They also show that the AA operated in the past and must be factored into paleoclimate reconstructions. Wendisch et al. [26] state that the Arctic has warmed much more rapidly than the rest of the world, and the degree of that warming exceeds the overall global warming rate by a factor of 2 to 3 . A significant impact of the AA is a reduction of the equator-to-pole temperature gradient, which will foster enhanced meridional flow. This can lead to greater variability in mid-latitude weather, to include heightened frequency of extreme weather events. Serreze \& Barry [27] argue that the AA can be linked to a strengthened thermohaline circulation, and its impacts could extend well beyond the Arctic. They also show that the AA is a prominent feature of the earth's paleoclimate.

Recent research shows that the AA is driven, in large part, by a process referred to as Atlantification (ATL). Chylek et al. [28] suggest that variability in AMOC is a major driver of Arctic temperatures, and that a high correlation exists between Arctic temperatures and the Atlantic Multi-decadal Oscillation (AMO). They go on to say that there is a strong relationship between the AMO and a wide array of Atlantic and other global climate phenomena. Mahajan et al. [29] argue that an intensified AMOC is associated with increased surface air temperatures (SAT) and negatively correlated with declines in sea ice in the Greenland, Barents, and Labrador Seas. Ricker et al. [30] demonstrate that ATL controls the sea-ice cover in the Barents Sea and that sea ice extent in the Arctic is approaching new lows. They further conclude that continued ATL should drive sea ice extent to even lower levels in the near future. Barton et al. [31] confirm the ATL of the Barents Sea and speculate that further warming will have far-reaching impacts on the Arctic climate. Csapo et al. [32] document a series of those impacts on the marine ecosystems in the Arctic, to include changes to the phytoplankton, zooplankton, fish communities, seabirds, Cetaceans, and polar bear populations. Also noted has been the increase of "neonative" species that have recolonized the region.

Of great importance is the fact that a number of other geophysical phenomena experienced similar shifts in 1995. As Figure 5 demonstrates, 1995 marked an abrupt shift in the AMO Index as it "flipped" from "negative" (i.e., cool) mode to "positive" (i.e., warm) mode. As defined by the National Oceanographic and Atmospheric Administration (NOAA) the AMO "... is an ongoing series of long-duration changes in the sea surface temperature of the North Atlantic Ocean, with cool and warm phases that may last for 20-40 years at a time and a difference of about $1^{\circ} \mathrm{F}$ between extremes. These changes are natural and have been occurring for at least the last 1,000 years" [33].

Dynamics of the AMO also affect temperatures for much of North America and Europe, drought conditions in the United States, hurricane frequency and intensity, the speed and intensity of the Gulf Stream; and the dynamics, variability, and spatial characteristics of El Niño. Knight, Folland \& Scaife [34], present regionally detailed impacts of these phase shifts, to include the following:

a) The Intertropical Convergence Zone (ITCZ) shifts northward during the warm phase and retreats southward during the cool phase. During the warm phase, precipitation is reduced 
in Northeast Brazil. Conversely, rainfall is above average for the region during the cool phase.

b) The positive phase brings greater rainfall to the Sahel of Africa, and a reduction in rainfall amounts during the negative phase. Again, these shifts in rainfall patterns are linked to the corresponding shifts in the ITCZ.

c) A positive AMO anomaly is associated with reduced rainfall in the United States and higher rainfall over Northwest Europe. There is also a tendency for increased rainfall in the North Atlantic and Northern Europe.

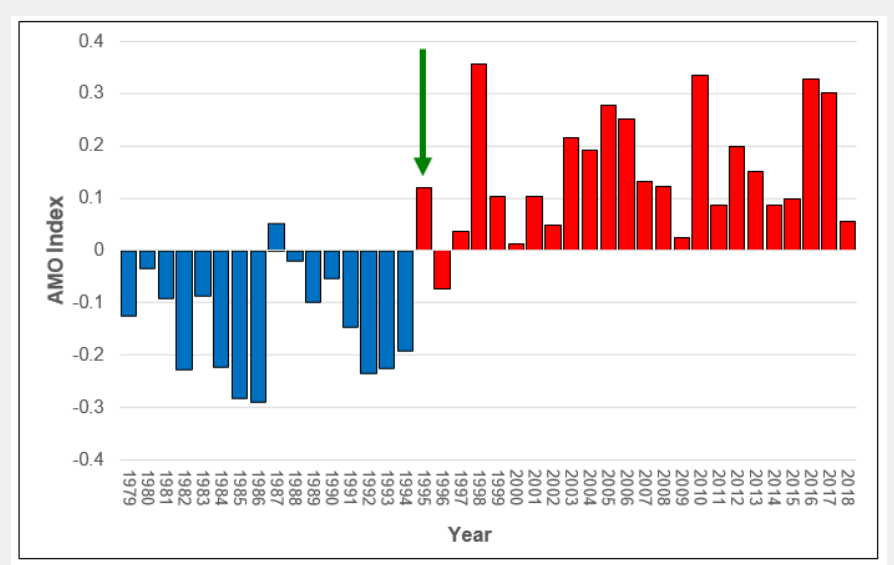

Figure 5: AMO Index. The green arrow identifies the 1995 data point. Blue bars indicate the cold AMO phase; red bars indicate the warm phase (https://psl.noaa.gov/data/correlation/amon.us.long.data).

Goldenberg et al. [35] show that Atlantic hurricane activity from 1995 through 2000 increased two-and a-half fold in response to warmer North Atlantic SST. Additionally, the Caribbean experienced a five-fold increase for that timeframe. In lockstep with the increase in hurricane frequencies, NOAA [36] shows that the Accumulated Cyclone Energy (ACE) for the North Atlantic also spiked higher in 1995 (Figure 6).

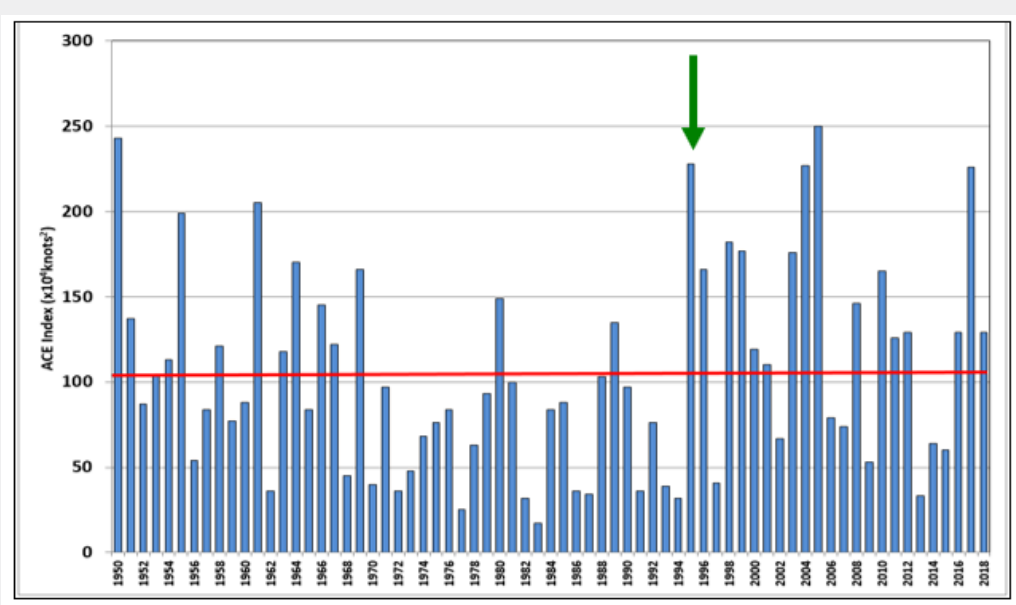

Figure 6: ACE North Atlantic. From NOAA [36]. The green arrow identifies the 1995 data point.

Increased hurricane energetics are significant as they are efficient vehicles for poleward heat transport and can further intensify the thermohaline circulation [37-39]. The warm phase of the AMO also affects monsoon strength and timing of monsoons in the East Asia and Indian sectors [40]. For both sectors, rainfall is increased and the Indian monsoon tends to withdraw later. A comprehensive review by Wang et al. [41] shows that a positive AMO is highly correlated with the Northern Hemisphere summer monsoon (NHSM) which, in turn, is correlated with what Wang et al. refer to as the "mega-ENSO Index." As the authors point out, the anomalously warm temperatures of the North Atlantic significantly affect the Pacific SST along with the NHSM precipitation and circulation dynamics. The combined effects of "mega-ENSO" and the AMO explains $73 \%$ of the total variation on the NHSM index and is most probably responsible for the intensification of NHSM in recent years.

Robson et al. [42] provide convincing evidence that the 1995 shift in the AMO was driven, in large part, by a strengthening of the AMOC (Figure 7). They show that rapid warming of the North 
Atlantic Sub Polar Gyre (SPG) was the result of a sudden surge in oceanic heat transported northward and conclude that this strengthening has persisted to the present.

In lockstep with the abrupt intensification of AMOC in 1995, Arctic air temperatures also began to increase that year. According to Przybylak [43], the 1995-through-2005 period saw the most intense warming recorded for the entire 1950-2005 period. The warming was most pronounced in autumn and winter, which was in excess of $2^{\circ} \mathrm{C}$, and was best expressed in the Pacific and Canadian regions. Furthermore, it appears that the significant change in surface air temperatures (SAT) in 1995 was caused by either natural forces, greenhouse gas feedbacks, or a combination of the two. In this author's view, natural forces are the overwhelming drivers here.

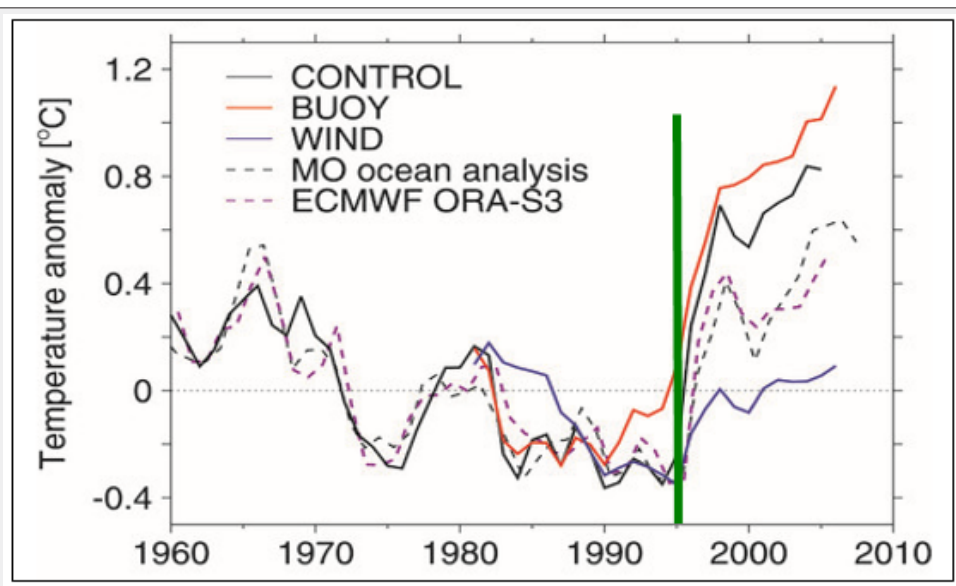

Figure 7: SPG temperature anomalies of the 0-500-meter layer from 1960-2010 [42]. The green bar identifies the 1995 data point. (C) 2012 American Meteorological Society used with permission.

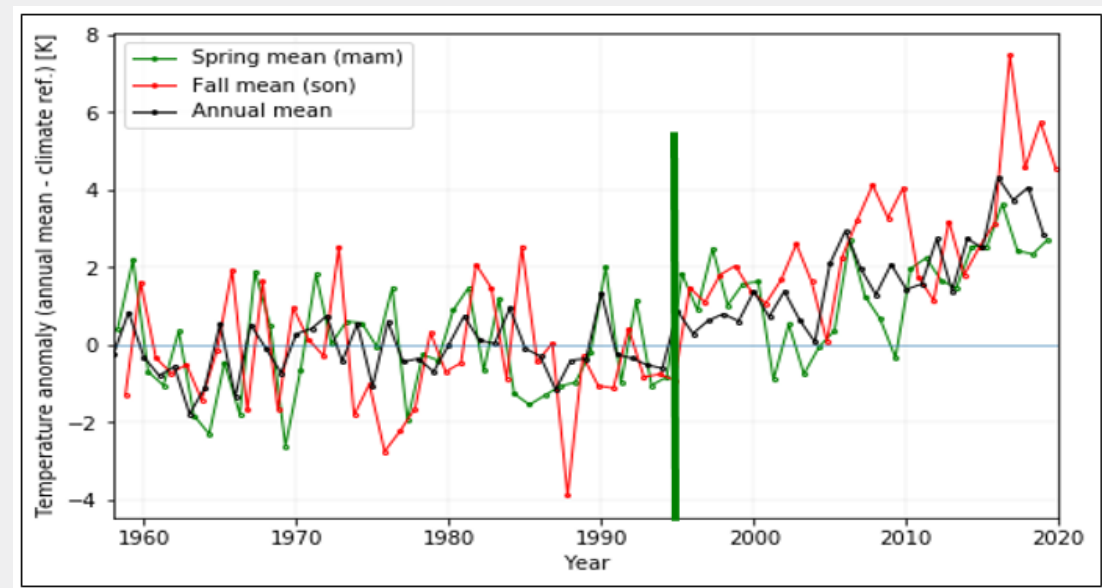

Figure 8: Arctic annual, spring, and fall mean temperatures above $80^{\circ} \mathrm{N}$. The green bar identifies the 1995 data point (http://ocean. dmi.dk/arctic/meant80n_anomaly.uk.php).

Temperature compilations from the Danish Meteorological Institute [44] above $80^{\circ} \mathrm{N}$ from 1958 (Figure 8 \& 9) clearly illustrate that the Arctic warming began abruptly in 1995 and that the most notable increases were realized in the autumn and winter seasons. In fact, the fall and spring temperatures jumped immediately after 1995 (Figure 8) whereas the winter means lagged but have shown the overall largest increase over time. Interestingly, the summer temperature curve (Figure 9) has remained essentially flat throughout the period.

Sea ice characteristics of the Arctic also changed significantly in 1995. Data from the National Snow and Ice Data Center show that 1995 was the break point for average sea ice area in the Northern Hemisphere (Figure 10): As the red trend line indicates, the sea ice area had plateaued from 1987 through 1994, and then dropped substantially in 1995 . The decline has persisted up to the present.

Regional sea ice trends in the Arctic were similarly impacted. As de la Castro et al. [45] report, 1995 was an inflection point for a number of Western Hudson Bay freeze parameters (Figure 11). The key takeaway from the study was that the ice-free period for the area increased by $3 \pm 0.8$ weeks for the 1979 through 2015 timeframe. 


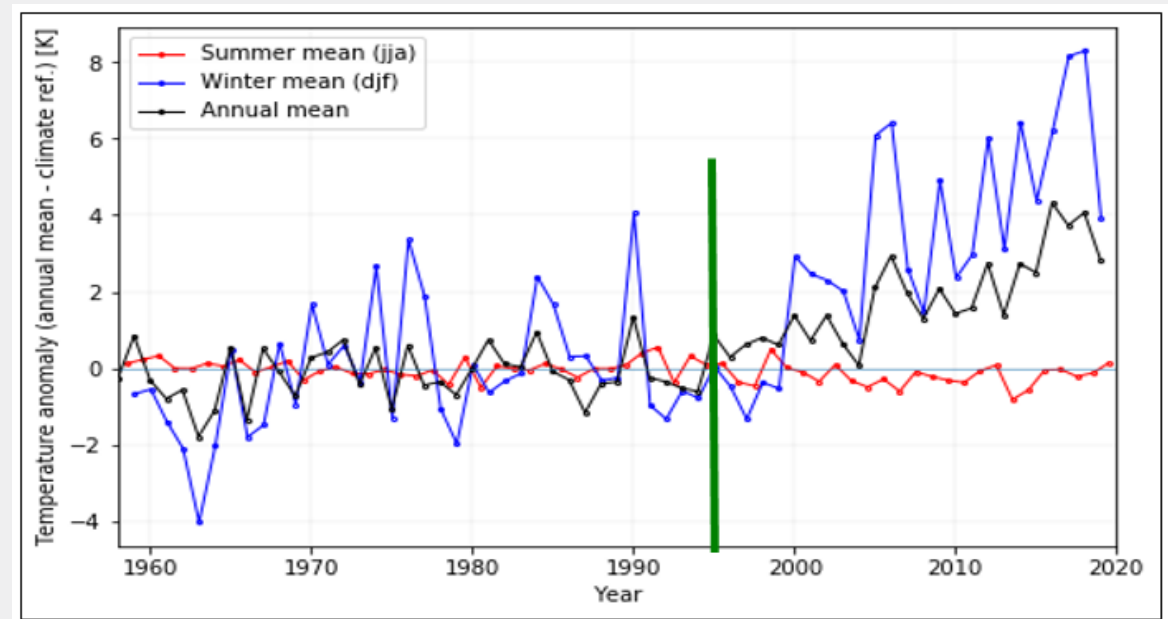

Figure 9: Arctic annual, winter, and summer mean temperatures above $80^{\circ} \mathrm{N}$. The green bar identifies the 1995 data point (http:// ocean.dmi.dk/arctic/meant80n_anomaly.uk.php).

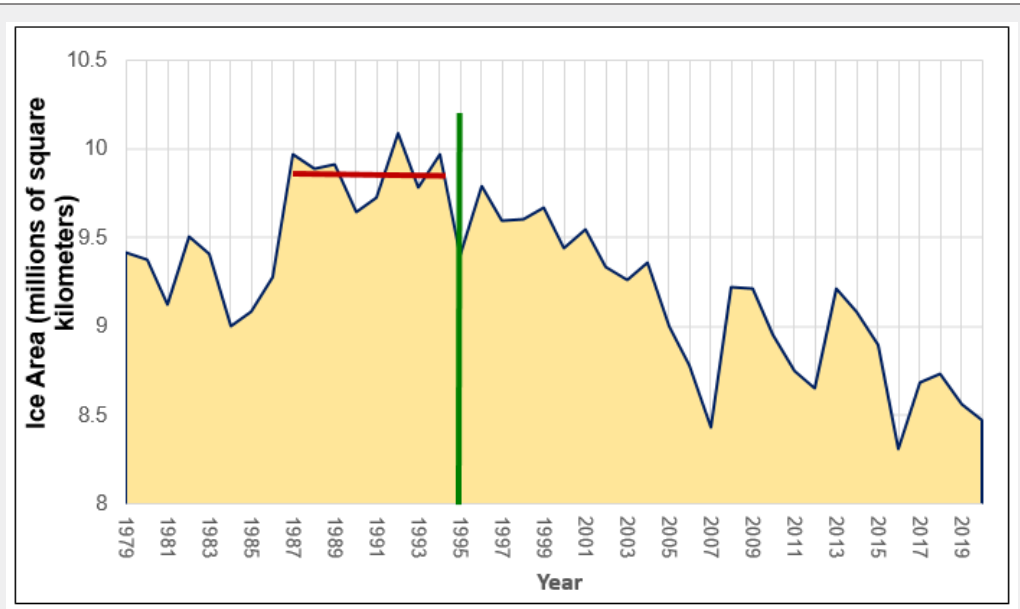

Figure 10: Sea Ice area, Northern Hemisphere. The green bar identifies the 1995 data point (https://masie_web.apps.nsidc.org/ pub//DATASETS/NOAA/G02135/seaice_analysis/Sea_Ice_Index_Monthly_Data_by_Year_G02135_v3.0.xlsx).

Hofer et al. [46] point to a concurrent decline in cloud cover as an ice loss amplifier for the Greenland Ice Sheet (Figure 12). They demonstrate that the Greenland ice sheets experienced a drop in both ice mass and summer cloud cover from 1995 to 2009 , creating a significant positive feedback response. Satellite observations showed that cloud cover declined by $0.9 \pm 0.3 \%$ per year.

Decreasing ice and cloud cover serve as strong positive feedbacks to Arctic warming. As Hudson [47], points out, the annually averaged radiative forcing from Arctic sea ice loss from 1979 to 2007 is approximately $0.1 \mathrm{~W} \mathrm{~m}{ }^{2}$. An ice-free Arctic

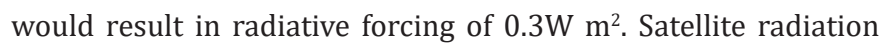
measurements from 1979 to 2011 indicate a reduction of Arctic planetary albedo from 0.52 to 0.48 from sea ice melt [25]. This has resulted in an additional $6.4 \pm 0.9 \mathrm{~W} \mathrm{~m}^{2}$ of solar energy available to the Arctic Ocean.
Yet another important geophysical parameter that changed abruptly after 1995 was the rate at which the magnetic north pole migrated (Figure 13). As Williams notes [48], that rate doubled in 1996 from its 1995 value, and suggested that the sudden jump in MOSZSA unlocked a "holding mechanism" that enabled rapid acceleration of dip pole drift. Deng et al. [49] demonstrate that 1995 also saw a significant shift in the Earth's geographic North Pole (i.e., its "true" pole as opposed to its dip pole). They hypothesize that a large uptick in glacial melt was responsible for driving the rapid polar drift towards the east.

\section{Conclusion}

A review of the literature from a variety of geophysical specialties, to include seismology, marine geology, oceanography, climatology, glaciology, and geodesy, reveals that a number of geophysical systems saw significant change commencing in 
1995 or shortly thereafter. The documented shifts in the earthatmosphere system include:

a) An abrupt increase in mid-ocean seismic activity.

b) A lagged (two-year) increase in global temperatures.

c) A rapid shift of the AMO from negative to positive.

d) A punctuated increase in North Atlantic hurricanes and North Atlantic ACE.

e) A significant change in the dynamics and variability of the NHSM and the El Niño/Southern Oscillation.

f) A rapid strengthening of the AMOC g) Sudden changes in the spring and fall Arctic temperatures, followed by a large jump in winter temperatures.

h) Sharp sea ice declines in the Arctic and sub-Arctic.

i) Accelerated ice loss for the Greenland Ice Sheet.

j) An abrupt decline in cloud cover over Greenland during the summer months.

k) Sudden changes in the rate of movement of the northern dip pole.

I) Rapid directional drift in the earth's geographic ("true") North Pole.

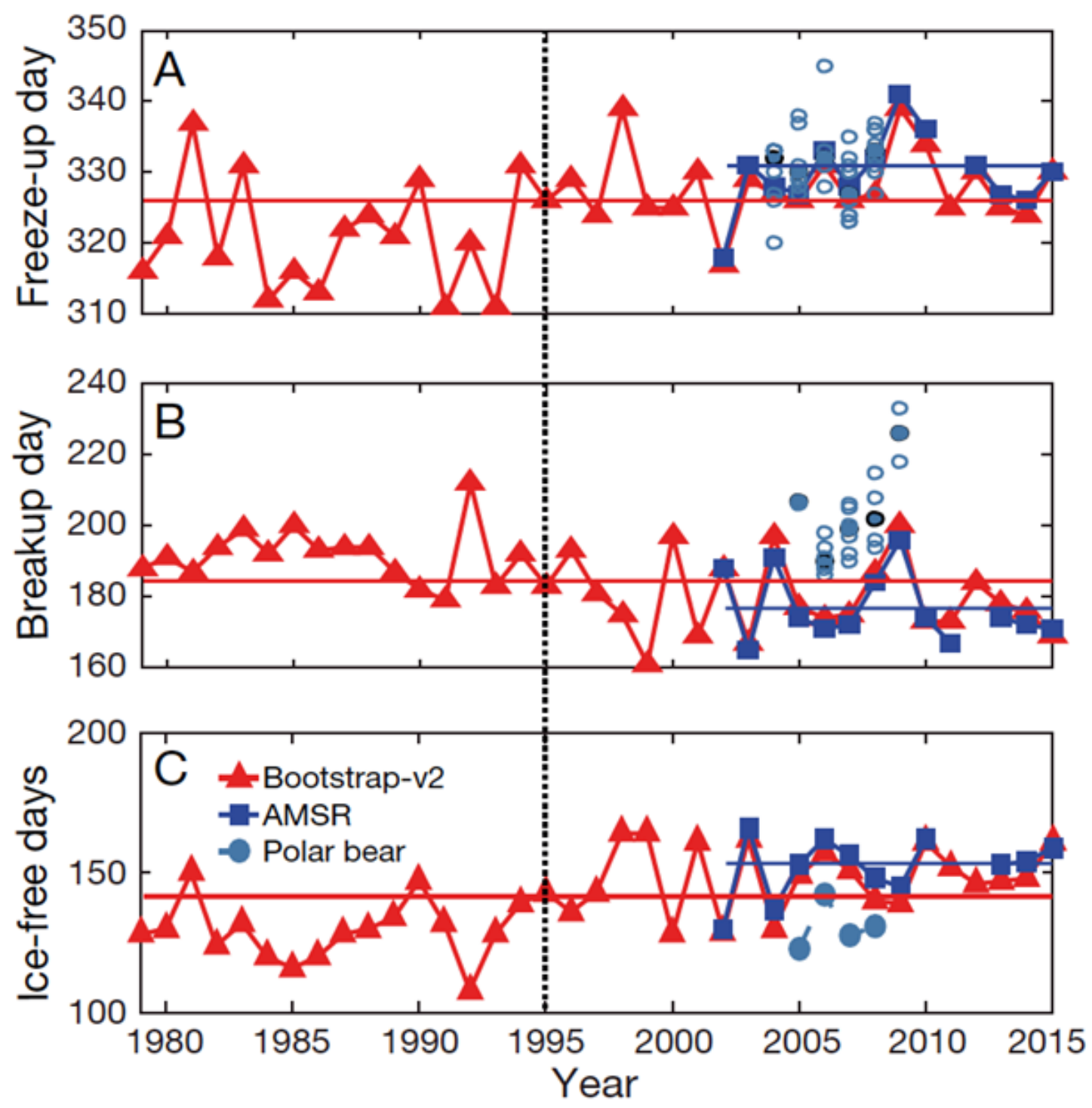

Figure 11: Western Hudson Bay freeze characteristics. 1995 is demarcated by the black dashed line [45]. @ 2017 Inter-Research and the Crown in the Right of Canada. 


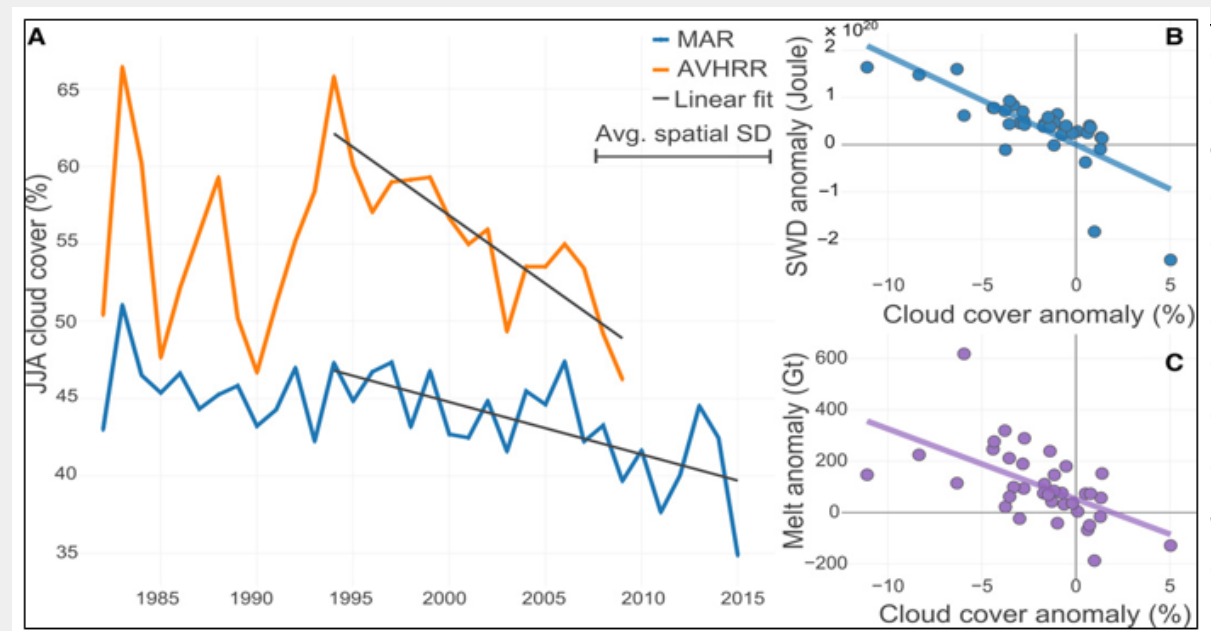

Figure 12: Declines in summer (June, July, and August) cloud cover over Greenland commencing in 1995 [46]. @ 2017 American Association for the Advancement of Science

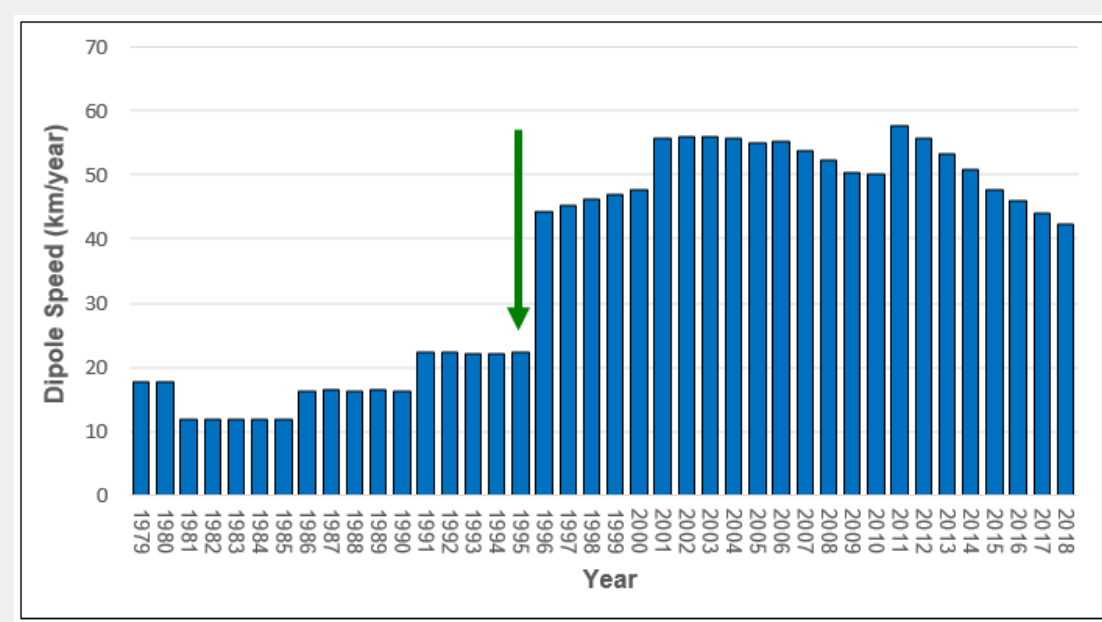

Figure 13: Dip pole speed (km) from 1979 to 2018. The green arrow designates 1995. (https://www.ngdc.noaa.gov/geomag/data/ poles/NP.xy).

While the geomagnetic and geodetic shifts are interesting in their own right, the focus will be on the interconnectedness of the other geophysical phenomena described above, as they are inextricably bound to the recent rise of global temperatures. The goal is to formulate a physically sound hypothesis as to why global temperatures rose sharply in 1997/1998. The synchronous geophysical changes presented here will serve as the basis of that hypothesis, which is articulated as follows: an increase in MOSZSA in 1995 was indicative of greater geothermal flux along the globe's mid-ocean spreading zones. This heightened flux intensified the thermohaline circulation, resulting in ATL and a strengthening of the AMOC. This gave rise to higher Arctic and North Atlantic SST. These higher SST were expressed as a shift of the AMO from a negative to a positive phase, creating an environment that was conducive to an increased frequency of North Atlantic hurricanes, a significant jump in ACE, stronger monsoons, and amplified El Niño episodes. These changes initiated a diminution of Arctic Sea ice, reduced cloud cover in the Greenland sector, and rising Arctic temperatures in the fall, spring and winter seasons. Moreover, geothermally driven thermobaric instability has been shown to amplify sea ice changes in the Arctic.

These interrelated phenomena are collectively referred to as the AA, the most prominent feature of the earth's recent warming. Acting in concert, all of these drivers can account for much of the warming the planet experienced in 1997. More importantly, the heightened mid-ocean geothermal flux that commenced in 1995 has persisted to the present, keeping global temperatures relatively stable yet elevated. Equally important, the hypothesis is strongly supported by the statistically significant correlation of GT and MOSZSA.

In conclusion, mid-ocean geothermal flux appears to be an important driver of global environmental change, and the evidence that other drivers and feedbacks are linked to that 
flux is compelling. Clearly, much more work needs to be done in this area. To ignore this line of inquiry will surely limit our ability to understand the intricacies of the earth-atmosphere system, dooming us to fall short of Alfred Wegener's noble goal of "unveiling the state of our planet.".

\section{References}

1. Wegener A (1929) The origin of continents and oceans. Translated from the fourth revised edition by John Biram. Dover, New York, 1967, USA, p. 256.

2. Viterito A (2016) The correlation of seismic activity and recent global warming. J Earth Sci Clim Change 7: 345.

3. Viterito A (2017) The correlation of seismic activity and recent global warming: 2016 update. Environ Pollut Climate Change 1: e103.

4. Viterito A (2018) Have global temperatures reached a tipping point? Environ Pollut Climate Change 2: 149.

5. Viterito A (2019) The relationship between mid-ocean spreading zone seismic activity and global temperatures remains strong through 2018. Int J Environ Sci Nat Res 20(3): 556039.

6. Meng F, Wong NY, Zhou H (2019) Power law relations in earthquakes from microscopic to macroscopic scales. Scientific Reports 9(10705).

7. Seropian G, Kennedy BM, Walter TR, Ichihara M, Jolly AD (2021) A review framework of how earthquakes trigger volcanic eruptions. Nat Commun 12(1004)

8. Baker ET (2009) Relationships between hydrothermal activity and axial magma chamber distribution, depth, and melt content. Geochem Geophys Geosyst 10(6)

9. Davis E, Becker K, Dziak R, Cassidy J, Wang K, et al. (2004) Hydrological response to a seafloor spreading episode on the Juan de Fuca ridge. Nature 430(6997): 335-338.

10. Lorenz EN (1968) Climatic Determinism. In: Mitchell JM (Ed.), Causes of Climatic Change. Meteorological Monographs, 8. American Meteorological Society, Boston, MA.

11. Lorenz EN (1964) The problem of deducing the climate from the governing equations. Tellus 16(1): 1-11.

12. Ballarotta M, Roquet F, Falahat S, Zhang Q, Madec G (2015) Impact of the oceanic geothermal heat flux on a glacial ocean state. Clim Past Discuss 11: 3597-3624

13. Thompson L, Johnson GC (1996) Abyssal currents generated by diffusion and geothermal heating over rises. Deep Sea Research Part I: Oceanographic Research Papers 43(2): 193-211.

14. Downes SM, Hogg AM, Griffies SM, Samuels BL (2016) The transient response of Southern Ocean circulation to geothermal heating in a global climate model. J Climate 29(16): 5689-5708.

15. Adcroft A, Scott J, Marotzke J (2001) Impact of geothermal heating on the global ocean circulation. Geophys Res Lett 28(9): 1735-1738.

16. Hofmann M, Morales Maqueda MA (2009) Geothermal heat flux and its influence on the oceanic abyssal circulation and radiocarbon distribution. Geophys Res Lett 36(3): L03603.

17. Urakawa LS, Hasumi H (2009) A remote effect of geothermal heat on the global thermohaline circulation. J Geophys Res Oceans 114: C07016.

18. Mullarney JC, Griffiths RW, Hughes GO (2006) The effects of geothermal heating on the ocean overturning circulation. Geophys Res Lett 33: L02607.
19. Scott JR, Marotzke J, Adcroft A (2001) Geothermal heating and its influence on the meridional overturning circulation. J Geophys Res 106(C12): 31141-31154.

20. Patara L, Böning CW (2014) Abyssal ocean warming around Antarctica strengthens the Atlantic overturning circulation. Geophys Res Lett 41(11): 3972-3978.

21. Carmack EC, Williams WJ, Zimmermann SL, McLaughlin FA (2012) The Arctic Ocean warms from below. Geophys Res Lett 39: L07604.

22. Björk G, Winsor P (2006) The deep waters of the Eurasian Basin, Arctic Ocean: Geothermal heat flow, mixing and renewal. Deep Sea Research Part I: Oceanographic Research Papers 53(7): 1253-1271.

23. McPhee MG (2003) Is thermobaricity a major factor in Southern Ocean ventilation? Antarctic Science 15(1): 153-160.

24. Holland MM, Bitz CM (2003) Polar amplification of climate change in coupled models. Climate Dynamics 21: 221-232.

25. Pistone K, Eisenman I, Ramanathan V (2014) Observational determination of albedo decrease caused by vanishing Arctic sea ice. Proceedings of the National Academy of Sciences 111(9): 3322-3326.

26. Wendisch M, Burrows JP, Crewell S, Dethloff K, Ebell K, et al. (2017) Understanding causes and effects of rapid warming in the Arctic Eos 98(8).

27. Serreze MC, Barry RG (2011) Processes and impacts of Arctic amplification: A research synthesis. Global Planetary Change 77(1-2): 85-96.

28. Chylek P, Folland CK, Lesins G, Dubey MK, Wang M (2009) Arctic air temperature change amplification and the Atlantic Multidecadal Oscillation. Geophys Res Lett 36: L14801.

29. Mahajan S, Zhang R, Delworth TL (2011) Impact of the Atlantic Meridional Overturning Circulation (AMOC) on Arctic surface air temperature and sea ice variability. J Climate 24(24): 6573-6581.

30. Ricker R, Kauker F, Schweiger A, Hendricks S, Zhang J, et al. (2021) Evidence for an increasing role of ocean heat in Arctic winter sea ice growth. J Climate 34(13): 5215-5227.

31. Barton BI, Lenn Y, Lique C (2018) Observed Atlantification of the Barents Sea Causes the Polar Front to limit the expansion of winter sea ice. Journal of Physical Oceanography 48(8): 1849-1866.

32. Csapó HK, Grabowski M, Węsławski JM (2021) Coming home - Boreal ecosystem claims Atlantic sector of the Arctic. Science of the Total Environment 771: 144817

33. https://www.aoml.noaa.gov/phod/amo_faq.php

34. Knight JR, Folland CK, Scaife AA (2006) Climate impacts of the Atlantic Multidecadal Oscillation. Geophys Res Lett 33(17): L17706.

35. Goldenberg SB, Landsea CW, Mestas-Nunez AM, Gray WM (2001) The recent increase in Atlantic hurricane activity: causes and implications. Science 293(5529): 474-479.

36. NOAA National Centers for Environmental Information, State of the Climate: Tropical cyclones for annual 2018.

37. Emanuel K (2001) Contribution of tropical cyclones to meridional heat transport by the oceans. J Geophys Res 106(D14): 14,771-14,781.

38. Hu A, Meehl GA (2009) Effect of the Atlantic hurricanes on the oceanic meridional overturning circulation and heat transport. Geophys Res Lett 36: L03702.

39. Gray WM, Sheaffer JD, Landsea CW (1997) Climate trends associated with multidecadal variability of Atlantic hurricane activity. In: Diaz HF Pulwarty RS (Eds.), Hurricanes. Springer, Berlin, Heidelberg, Germany, p. 310. 
40. Lu R, Dong B, Ding H (2006) Impact of the Atlantic Multidecadal Oscillation on the Asian summer monsoon. Geophys Res Lett 33(24): L24701.

41. Wang B, Liu J, Kim H, Webster PJ, Yim SY, et al. (2013) Northern Hemisphere summer monsoon intensified by mega- El Niño/southern oscillation and Atlantic multidecadal oscillation. Proceedings of the National Academy of Sciences 110(14): 5347-5352.

42. Robson J, Sutton R, Lohmann K, Smith D, Palmer MD (2012) Causes of the rapid warming of the North Atlantic Ocean in the mid-1990s. J Climate 25(12): 4116-4134.

43. Przybylak R (2007) Recent air-temperature changes in the Arctic. Annals of Glaciology 46(1): 316-324.

44. http://ocean.dmi.dk/arctic/meant80n_anomaly.uk.php
45. Castro de la Guardia L, Myers PG, Derocher AE, Lunn NJ, Terwisscha van Scheltinga AD (2017) Sea ice cycle in western Hudson Bay, Canada, from a polar bear perspective. Mar Ecol Prog Ser 564: 225-233.

46. Hofer S, Tedstone AJ, Fettweis X, Bamber JL (2017) Decreasing cloud cover drives the recent mass loss on the Greenland Ice Sheet. Sci Adv 3(6): e1700584

47. Hudson SR (2011) Estimating the global radiative impact of the sea ice-albedo feedback in the Arctic. J Geophys Res 116(D16).

48. Williams B (2016) The correlation of North Magnetic Dip Pole motion and seismic activity. J Geol Geophys 5: 262.

49. Deng S, Liu S, Mo X, Jiang L, Bauer-Gottwein P (2021) Polar drift in the 1990s explained by terrestrial water storage changes. Geophys Res Lett 48(7): e2020GL092114.

Your next submission with Juniper Publishers will reach you the below assets

- Quality Editorial service

- Swift Peer Review

- Reprints availability

- E-prints Service

- Manuscript Podcast for convenient understanding

- Global attainment for your research

- Manuscript accessibility in different formats

( Pdf, E-pub, Full Text, Audio)

- Unceasing customer service

Track the below URL for one-step submission https://juniperpublishers.com/online-submission.php 